\title{
Gripinis sindromas: du panašūs, bet skirtingi klinikiniai atvejai
}

\author{
Jolanta Burdulyte் \\ Marijampolès ligoninè
}

\section{PIRMASIS KLINIKINIS ATVEJIS}

\section{Ligos anamnezè}

2009 m. lapkričio $17 \mathrm{~d}$. vakarą i Marijampolès ligoninès Vidaus ligų skyriụ buvo paguldytas 38 metụ vyras, kuris skundèsi karščiavimu iki $39^{\circ} \mathrm{C}$, gerklès perštejimu, sausu kosuliu, dusuliu fizinio krūvio metu, skausmu krūtinèje kosint, ypač dešiniajame šone, silpnumu. Prieš 2 paras pacientas buvo sunkiai dirbęs miške, sušalo ir vakare prasidejjo febrilus karščiavimas, atsirado gerklès skausmas. Gydèsi savarankiškai namuose antipiretikais. Savijauta negerëjo, febrilus karščiavimas tęsèsi, atsirado kosulys, dusulys, krūtinès skausmas, todèl pacientas kreipèsi mediku pagalbos.

\section{Tyrimų duomenys \\ Objektyvus tyrimas}

Atvykusio paciento bendroji būklè patenkinama, kūno temperatūra $-39,2^{\circ} \mathrm{C}$, akiụ junginès, tonzilès, žiočiu lankai paraudę, periferiniai limfmazgiai nepadideję, liežuvis sausas, padengtas balkšvo apnašo, kraujo ịsotinimas deguonimi matuojant pulsoksimetru $\left(\mathrm{SpO}_{2}\right)-$ 92 proc., kvėpavimo dažnis - $18 \mathrm{k} . / \mathrm{min}$., plaučiuose alsavimas vezikulinis, abipus apatinèse dalyse smulkūs drègni karkalai, širdies veikla ritmiška, pulsas - 100 k./min., AKS - 140/90 mm Hg, kitos sistemos - be pokyčių.

\section{Laboratoriniai tyrimai}

Ištirtas CRB - $161 \mathrm{mg} / \mathrm{l}$, kiti laboratoriniai tyrimai (bendrasis ir biocheminis kraujo tyrimai, šlapimo tyrimas) - be patologiniu pokyčių.

\section{Instrumentiniai tyrimai}

Krūtinès ląstos rentgenogramoje (1 pav.) matyti susiliejanti stambiažidininè infiltracija abiejų plaučių apatinèse dalyse.

\section{Klinikinè diagnozè}

Vidaus ligų gydytojas, ịvertinęs klinikinius simptomus, objektyvaus tyrimo duomenis, kraujo ir krūtinès ląs- tos rentgeninio tyrimo rezultatus, nustate diagnozę Pneumonia lobi inferioris bilateralis.

\section{Gydymas}

Pacientui skirta ị veną leidžiamo penicilino po $2 \mathrm{mln}$. $4 \mathrm{k}$. per parą, geriamojo ibuprofeno po $400 \mathrm{mg} 3 \mathrm{k}$., infuzoterapija kristaloidu tirpalais.

\section{Ligos eiga \\ Marijampolés ligoninès vidaus ligu skyrius}

Po 36 valandụ paciento būklè nebuvo pagerèjusi, ir toliau karščiavo iki $40^{\circ} \mathrm{C}$, sustiprejo dusulys. Kartotinai ištirtas CRB - jo koncentracija buvo padidejusi iki 225 $\mathrm{mg} / \mathrm{l}$. Arterinio kraujo duju tyrimas rode hipoksemiją: $\mathrm{pH}-7,399, \mathrm{pCO}_{2}-41,7 \mathrm{~mm} \mathrm{Hg}, \mathrm{pO}_{2}-43 \mathrm{~mm} \mathrm{Hg}$, $\mathrm{SaO}_{2}-80$ proc. Koreguotas antibakterinis gydymas penicilinas pakeistas cefuroksimu po $1,5 \mathrm{~g} 3 \mathrm{k}$. ì veną, tęsta infuzoterapija kristaloidu tirpalais, pradètas gydymas deguonimi per nosini kateteri.

Tos pačios paros antroje pusèje paciento būklè smarkiai pablogejjo, atsirado ryškus kvejpavimo nepakankamumas: priverstiné sedima padètis, lūpu ir galūnių cianozè, kvèpavimo dažnis - $32 \mathrm{k}$./min., plaučiuose alsavimas vezikulinis, difuziniai sausi birzgiantys karkalai, abipus apatinèse dalyse smulkūs drègni karkalai, pulsas - 92 k./min., AKS - 100/70 mm Hg. Kartotinis kraujo dujų tyrimas rode gilejjančią hipoksemiją: $\mathrm{pO}_{2}-$ $39,1 \mathrm{~mm} \mathrm{Hg}, \mathrm{SaO}_{2}-73,9$ proc., todèl pacientas toliau gydyti iškeltas į reanimacijos skyrių, kur paskirta oksigenoterapija per veido kaukę, tęstas antibakterinis gydymas cefuroksimu, infuzoterapija.

Po pusès paros paciento būklè dar labiau pablogèjo, išsivystė cianozė ir mikrocirkuliacijos sutrikimai visame kūne, kraujo įsotinimas deguonimi sumažèjo iki 70 proc., todèl pacientas intubuotas, pradèta dirbtinè plaučiu ventiliacija. Atliktų papildomų tyrimų rezultatai: biocheminis kraujo tyrimas: GPT - 44 U/l, GOT - 120 $\mathrm{U} / \mathrm{l}, \mathrm{CRB}-237 \mathrm{mg} / \mathrm{l}$, prokalcitoninas - 0,74 $\mathrm{ng} / \mathrm{ml}$; echokardiografija: IF - 47 proc., širdies ertmès nepadidejjusios, sieneliu storis normalus, perikardo ertmèje skysčio kiekis normalus; pilvo organų ultragarsinis ty- 
rimas: kepenys saikingai padidejusios, dismetabolinès, blužnis padidèjusi, kiti organai - be pokyčių. Pakartota krūtinès ląstos rentgenograma (2 pav.): plaučių oringumas sumažèjęs dèl edemos ir galimos infiltracijos, kuri intensyviausia dešiniojo plaučio viršutinèje ir vidurinejje dalyse, plaučių šaknys plačios, stazinès.

Iš pediatrijos skyriaus gydytojų sužinota, kad ligonio posūniui nustatytas pandeminio gripo $\mathrm{H} 1 \mathrm{~N} 1$ virusas, todèl paimtas nosiaryklès tepinèlis virusologiniam tyrimui, pradètas gydymas Tamiflu po $150 \mathrm{mg} 2$ kartus per parą. Kadangi būklè liko sunki, vystèsi bakterieminis šokas, arterinis kraujo spaudimas sumažejo iki 90/60 mm Hg, ligonis toliau gydyti perkeltas ị KMUK Intensyviosios terapijos skyrių.

\section{KMUK Intensyviosios terapijos skyrius}

KMUK Intensyviosios terapijos skyriuje atlikti tyrimai diagnozei patikslinti: šlapimo tyrimas dèl Legionella pneumophilla antigeno buvo neigiamas, kraujo pasėlyje išaugo Achromobacter spp. Sužinotas nosiaryklès tepinèlio virusologinio tyrimo atsakymas: identifikuotas sezoninio gripo virusas H3N2.

Papildyta klinikinè diagnozè: Grippe. Pneumonia bilateralis gravis. Insufficientia pulmonalis acuta. Dystress - syndromum respiratorium. Sepsis (Achromobacter spp).

KMUK Intensyviosios terapijos skyriuje skyriuje pacientas gydytas 9 paras, taikyta invazinè dirbtinè plaučių ventiliacija, i veną lašinta dopamino, pagal kraujo pasèlio rezultatus ir antibiotikogramą ì veną skirta ceftazidimo po $2 \mathrm{~g} 3 \mathrm{k}$. per parą, tęstas antivirusinis gydymas Tamiflu po $75 \mathrm{mg} 2 \mathrm{k}$. per parą.

Paciento būklè pradejo gerèti, nustojo karščiuoti, normalizavosi arterinis kraujo spaudimas, mažėjo CRB koncentracija kraujyje: $213,5 \rightarrow 175 \rightarrow 34,2 \mathrm{mg} / \mathrm{l}$, kraujo dujų tyrime išnyko hipoksemijos požymiai: $\mathrm{pH}$ 7,43, $\mathrm{pCO}_{2}-44,2 \mathrm{~mm} \mathrm{Hg}, \mathrm{pO}_{2}-62 \mathrm{~mm} \mathrm{Hg}, \mathrm{SaO}_{2}-$ 94 proc., krūtinès ląstos rentgenogramoje (3 pav.) matyti, kad neliko plaučiuc edemos, sumažejo infiltracija viršutinèse dalyse, šiek tiek sumažèjo infiltracija apatinèse abiejų plaučių dalyse.

Ligonis perkeltas ị KMUK Pulmonologijos ir alergologijos skyrių, kur 7 dienas tęstas antibakterinis gydymas, skirta kvėpavimo takų kineziterapija. Baigus gydymą, pacientas išsiųstas ị Birštono „Versmès“ sanatoriją antro reabilitacijos etapo.

Praejjus mėnesiui po išrašymo iš Birštono „Versmès“ sanatorijos, pacientas jautèsi patenkinamai, profilaktiškai atvyko pas šeimos gydytoją, atliktoje krūtinès ląstos rentgenogramoje patologinių pokyčių plaučiuose nepastebèta.

\section{Apibendrinimas}

Vèlyvą rudení, žiemą, ankstyvą pavasarị febriliai karščiuojančiam ligoniui nustačius visuomeneje igytos pneumonijos diagnozę, reikia pagalvoti, ar tai nèra gripo komplikacija, ir atsižvelgti i gripo diagnostikos kriterijus:

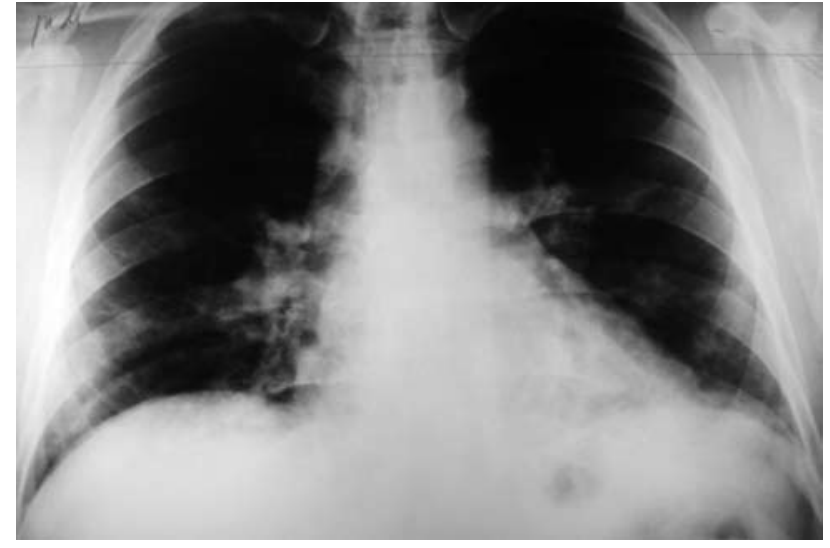

1 pav. Tiesinè krūtinès ląstos rentgenograma:

susiliejanti stambiažidininè infiltracija abiejų plaučių apatinèse dalyse

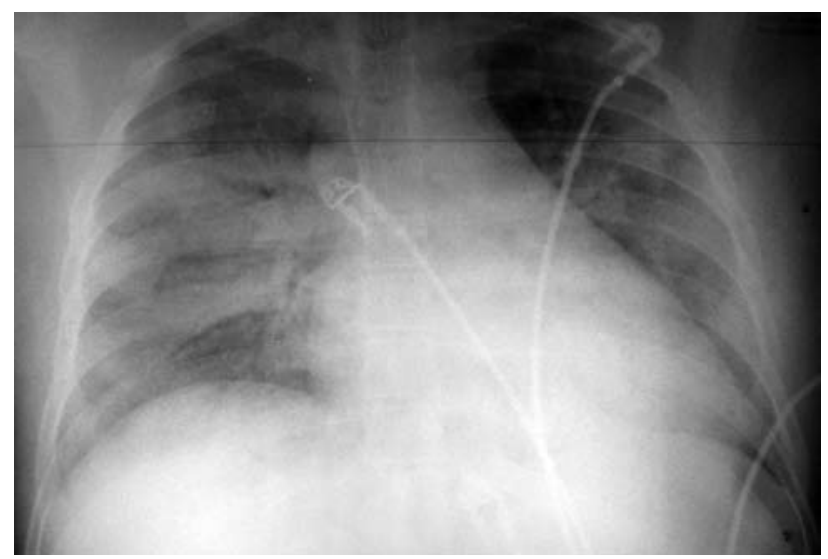

2 pav. Tiesinè krūtinès ląstos rentgenograma:

sumažèjęs plaučių oringumas dèl edemos ir galimos infiltracijos, kuri intensyviausia dešiniojo plaučio viršutineje ir vidurinejje dalyse, plaučių šaknys plačios, stazinès

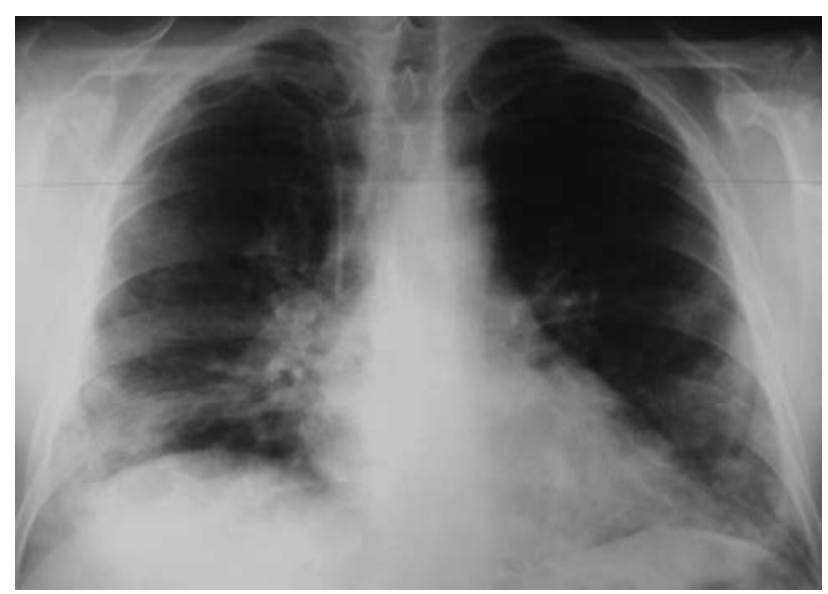

3 pav. Tiesinè krūtinès ląstos rentgenograma:

sumažejusi infiltracija viršutinèse dalyse, infiltracija apatinėse abieju plaučių dalyse sumažèjusi nedaug

- sezoniškumas: vėlyvas ruduo, žiema, ankstyvas pavasaris;

- epidemiologinè situacija šalyje;

- kontaktas su karščiuojančiu, peršalimo ligomis sergančiu ligoniu; 
1 lentelè. Kraujo dujų tyrimai atvykus i ligoninę

\begin{tabular}{llll}
\hline & Vyras & Žmona & Sūnus \\
\hline $\mathrm{pH}$ & 7,411 & 7,367 & 7,44 \\
\hline $\mathrm{pCO}_{2}$ & $37,1 \mathrm{~mm} \mathrm{Hg}$ & $29,9 \mathrm{~mm} \mathrm{Hg}$ & $36 \mathrm{~mm} \mathrm{Hg}$ \\
\hline $\mathrm{pO}_{2}$ & $83,3 \mathrm{~mm} \mathrm{Hg}$ & $35,6 \mathrm{~mm} \mathrm{Hg}$ & $76,7 \mathrm{~mm} \mathrm{Hg}$ \\
\hline $\mathrm{SaO}_{2}$ & 96,7 proc. & 90 proc. & 96 proc. \\
\hline $\mathrm{COHb}$ & 49,4 proc. & 45 proc. & 35,7 proc. \\
\hline
\end{tabular}

2 lentelè. Karboksihemoglobino koncentracija kraujyje prieš gydymą ir po jo

\begin{tabular}{llll}
\hline & Vyras & Žmona & Sūnus \\
\hline $\mathrm{COHb}$ (prieš) & 49,4 proc. & 45 proc. & 35,7 proc. \\
\hline $\mathrm{COHb}$ (po) & 1,9 proc. & 1,3 proc. & 0,8 proc. \\
\hline
\end{tabular}

- klinikiniai simptomai: staiga prasidejjęs febrilus karščiavimas, raumenų, galvos, gerklès skausmai, kosulys.

Ittarus plaučių uždegimu ir kvėpavimo nepakankamumu komplikuotą gripą, nesvarbu, kokia ligos trukmè, gydyti iš karto skiriamas antivirusinis vaistas, nelaukiant nosiaryklès virusologinio tyrimo atsakymo.

\section{ANTRASIS KLINIKINIS ATVEJIS}

\section{Nusiskundimai ir ligos anamnezè}

2006 m. kovo mėnesio pradžioje 32 metų bendrosios praktikos gydytoja staiga sukarščiavo iki $39^{\circ} \mathrm{C}$, pajuto nosies užgulimą, gerklès perštejjimą, galvos ir raumenų skausmą, silpnumą. Gydytoja įvertinus ją kamuojančius simptomus, diagnozuoja sau gripą, nes tuo metu Marijampolès mieste buvo didelis sergamumas šia liga, darbe bendravo su gripu sergančiais pacientais. Po kelių valandų febriliai sukarščiavo ir minètus simptomus pajuto gydytojos vyras ir šešiametis sūnus. Visi trys gydèsi namuose: gulejjo lovoje ir gèrè antipiretiką paracetamoli.

Gydytojos vyras, pats nebūdamas medikas ir nepasitikèdamas žmonos nuomone, pasikvietė $\mathfrak{i}$ namus šeimos drauges - vidaus ligu gydytojas. Šios atvyko i namus ir apžiūrèjo ligonius.

\section{Objektyvaus tyrimo duomenys}

Būklè vidutinio sunkumo, visi ligoniai vangūs, nenoriai atsakinèjo ì klausimus, kūno temperatūra siekè $40^{\circ} \mathrm{C}$, paraudusios akių junginės, liežuvis sausas, tachikardija, kitos sistemos - be ženklesnių patologinių pokyčių.

\section{Preliminari diagnozè}

Pagal nusiskundimus, ligos anamnezę, objektyvaus tyrimo duomenis neabejojant nustatoma diagnozè -
Grippe. Dehydratatio $I I^{\circ}$.

Esant ryškiai intoksikacijai ir dehidratacijai, nuspręsta, kad reikalingas stacionarinis gydymas, iškviesta greitoji medicinos pagalba. Kol ji atvyko, ženkliai pablogèjo sergančio vyro savijauta, išsivystė prieblandinè sąmonès būklè, traukuliai, dèl to ì veną suleista diazepamo.

Patikslinti karščiavimo priežastị ir nustatyti teisingą diagnozę padejjo atsitiktinumas, kai ị namus ịejęs „greitosios" vairuotojas pasake užuodžiąs smalkių kvapą.

Visi trys šeimos nariai nugabenti ì Marijampolès ligoninę, jiems atliktas kraujo dujų tyrimas: nustatyta padidejusi karboksihemoglobino koncentracija (1 lentelè). Tyrimai įrodè vidutinio sunkumo apsinuodijimą smalkėmis.

Diagnozę patvirtino ir dujų avarinès tarnybos išvados: didelè anglies monoksido koncentracija gyvenamųjų patalpų ore, gamtinių dujų šildymo sistemos veiklos sutrikimas.

\section{Klinikinè diagnozè}

Intoxicatio acuta accidentalis inhalationalis cum Carbonei monoxydo moderata. Hyperthermia.

\section{Gydymas}

Pacientams paskirtas gydymas deguonimi, ir jau po kelių valandų išnyko karščiavimas, tachikardija, vangumas, galvos, raumenu skausmai, normalizavosi karboksihemoglobino koncentracija kraujyje (2 lentelè). Kitą parą visi trys išrašyti ì namus.

\section{Apibendrinimas}

Šiuo atveju karščiavimą, galvos skausmus sukèlè smegenų brinkimas dèl toksinio smalkių poveikio. Apsinuodijimą smalkėmis itin svarbu ịtarti tada, kai susirgimas grupinis. Apsinuodijimas gali pasireikšti vienu ar keliais iš šių simptomų:

- galvos skausmas, ūžimas ausyse;

- pykinimas, vėmimas, epigastriumo skausmai;

- silpnumas, mieguistumas, vangumas, adinamija;

- hipertermija $\left(40^{\circ} \mathrm{C}\right)$, gripinis sindromas;

- alpimai, haliucinacijos, sąmonès sutrikimas.

Smalkès yra bekvapès dujos (kartais užuodžiami kiti šalutiniai produktai), susidarančios degant kurui, turinčiam anglies junginių (malkoms, akmens angliai, gamtinèms dujoms), kai degimo aplinkoje nepakankama deguonies anglies dvideginiui $\left(\mathrm{CO}_{2}\right)$ susidaryti (pvz., esant prastai ventiliacijai). Gyvenamuosiuose namuose pravartu įrengti anglies monoksido detektoriuc, kiekvienais metais patikrinti namo šildymo ịrenginius, būsto ventiliacinès sistemos efektyvumą.

\section{LITERATŪRA}

1. T. V. Kajokas, J. Šurkus, A. Stonys, R. Purvaneckas, R. Badaras, V. Kuzminskis, T. Jovaiša, R. Mačiulaitis, D. Vaitkaitis, J. Grebelienè, V. Žilinskaitè. "Klinikinè toksikologija“, $2002 \mathrm{~m}$.

2. http://www.emedicinehealth.com/carbon_monoxide_poisoning/article em.htm

3. http://www.who.int/csr/disease/influenza/pandemic/en/ 